\title{
Evaluation and Study on Allocation Efficiency of Private University Educational Resources Based on DEA Model
}

\author{
Bin $\mathrm{Li}$ \\ Management Department \\ School of Business and Trade \\ Huanghe Science and Technology College \\ Zhengzhou, Henan, China 450063
}

\begin{abstract}
The DEA evaluation and empirical study has been conducted for the educational resources allocation efficiency of 10 Chinese private universities in 2012 using the data envelopment analysis (DEA) mode from three aspects of overall technical efficiency, pure technical efficiency and scale efficiency against the problems exist in the allocation efficiency of China's private university educational resources and the construction of efficiency evaluation index system of private university resources. The results show that such problems as relatively low overall technical efficiency, low overall scale efficiency and school-running scale effect hasn't been given full play exist in the allocation of Chinese private university educational resources.
\end{abstract}

Keywords-private universities; educational resources; efficiency evaluation; data envelopment analysis (DEA)

\section{INTRODUCTION}

Private Universities refer to the social-oriented colleges and other educational institutions organized by enterprises, institutions, social groups and other social organizations and individual citizens using non-state financial education budget. Chinese private universities have already developed for 30 years. As of June 21, 2013, regular institutions of higher education (excluding independent college) in the whole country totaled 2198, among which 424 independent private colleges are established. As a result, Chinese private universities are playing an increasingly important role in the cause of education. However, because of the short history and characteristics of private universities, their development is facing a dilemma of inadequate educational resources investment and low utilization efficiency of resources. Therefore, to improve the educational resources utilization efficiency of private universities and to enhance school running efficiency of private universities have become an important issue in the education sector and academia.

Utilization efficiency of higher educational resources refers to the ratio between input and output of educational resources, including education input factors (manpower, material and finance) efficiency, education scale efficiency, education quality efficiency, school management efficiency, etc., reflecting the effective allocation capacity of educational resources of colleges and universities. Current researches on efficiency of resource allocation of higher education mainly from the following perspectives: (1) Study on Macro Mechanism of Resource Allocation Efficiency of Higher Education. Most researchers believe that there are two modes of higher educational resources allocation, namely government and market. The quasi-public product attributes of higher education and the transition period currently located has determined the current allocation mode of higher education must be the only hybrid of government and market of "market-oriented on the micro and government regulation-oriented on the macro". Although there are different voices, such as Clark (1994) [1] and Kang Ning (2004) [2] hold the opinion that resource allocation of higher education is the product of interaction of market, government and academy. But in general, they all agree with that resource allocation mode of higher education is a multimode "hybrid", of which government and market are the two most basic allocation modes. And the nature, applicable scope, reasonableness and necessity of the two modes have been discussed. (2) Empirical Study and Institutional Reason Study on Allocation Efficiency of Higher Education Resources. Some scholars have adopted empirical research methods, and confirmed the inefficiencies of higher education resources caused by irrational allocation through large samples. For example, Zhou Wei (2006) [3] has conducted empirical analysis taking 53 colleges and universities directly under the Ministry of Education as an example on the basis of research framework of data envelopment analysis (DEA) method, and found that irrational allocation of higher education resources among universities is the main reason for the loss of educational resources efficiency. So he advocates improving educational resource utilization efficiency through perfecting of funding and budgeting system of higher education and promotion of resource flow among universities. Liu Yarong (2011) [4] adopts the DEA method for the study on Chinese schoolrunning efficiency with the conclusion as follows: among 55 universities, 46 DEA effective, 6 non-DEA effective; among 32 research-oriented universities of engineering, 99 effective, 33 non-effective; among 125 teaching-oriented universities in engineering, 71 effective, 54 non-effective. In addition, 
Chen Tong (2012)[5] has discussed the relative effectiveness of input and output of universities in the western region with the results showing that most universities in western region are in a status of non-DEA effective and the stage of increasing returns to scale. These studies have described the inefficiencies caused by irrational allocation of resources from a macro perspective, and demonstrated the relevance between the mode and efficiency of higher education resource allocation.

In summary, relevant scholars have conducted quite al lot studies on allocation efficiency of higher education resources, but there are still research space can be expanded as follows: (1) as for research ideas, they tend to lay emphasis on the allocation efficiency study from the perspective of macro allocation mechanism and micro level of universities, and there are less studies on of utilization efficiency of higher education resources from the micro level; (2) as the study object, there is a huge research expansion space as there are relatively less researches on educational resource allocation efficiency of private universities. Under such a context, the data envelopment analysis (DEA) model is proposed to be adopted to measure the educational resource efficiency of Chinese typical private universities through the establishment of input-output index system of educational resource efficiency evaluation of private universities, and to analyze its overall technical efficiency, pure technical efficiency and scale efficiency. Moreover, analyze relevant factors affecting the educational resource efficiency of private universities on the basis of the above-mentioned, and put forward the institutional arrangements, measures and suggestions for improving resource allocation efficiency of private universities

\section{DEA EVALUATION MODEL FOR PRIVATE UNIVERSITY EDUCATION RESOURCE EFFICIENCY}

Data envelopment analysis (DEA) is a new systemic analysis method developed by the famous American operational research experts, such as A.Charnel and WW Cooper, based on the concept of "relative efficiency evaluation", DEA method has many advantages such as simple calculation method and diversified evaluation result without the requirements of index weight estimates and setting the explicit function relationship between input and output in advance. Therefore, it is particularly suitable for the relative efficiency evaluation of complex systems with multi-input and multi-output.

According to the general theory of DEA modeling [6], and in combination with the actual situation of educational resource efficiency evaluation of private universities, the DEA model (C2R) for measuring overall technical efficiency of private university education resource and the DEA model (C2GS2) for measure their pure technical efficiency and scale efficiency are established as follows:

Regard each private university to be evaluated as a Decision Making Unit (DMU), suppose the number of DMU is $n$, each DMU has $m$ kinds of input factors and $n$ kinds of output factors, then the input and output data of the $\mathrm{j}$-th $\mathrm{DMU}(\mathrm{DMUj})$ can be expressed using vector as:
$X_{j}=\left(x_{1 j}, \ldots, x_{n j}\right)^{T}>0$ and $Y_{j}=\left(y_{1 j}, \ldots, y_{s j}\right)^{T}>0, j=1, \ldots, n$.Where,

$x_{i j}$ represents the i-th kind input volume of DMUj, and $y_{r j}$ represents the r-th kind output volume of DMUj. Suppose the j0-th DMU (DMUj0) is the decision making unit to be evaluated (for convenience, record DMUj0 as DMU0, the same below), the input and output vectors of it are $X_{0}$ and $Y_{0}$ respectively, then the relative efficiency evaluation DEA model of DMU0 based on input is (C2R model):

$$
\left\{\begin{array}{l}
\min \theta \\
\text { s.t. } \\
\sum_{j=1}^{n} \lambda_{j} X_{j}+S^{-}=\theta X_{0} \ldots \ldots \ldots \ldots \ldots(1) \\
\sum_{j=1}^{n} \lambda_{j} Y_{j}-S^{+}=Y_{0} \\
\lambda_{j} \geq 0 ; j=1, \ldots, n ; S^{-} \geq 0 ; S^{+} \geq 0
\end{array}\right.
$$

According to DEA theory, suppose the optimal solutions of the above linear programming (1) are $\lambda^{*}, S^{-*}, S^{+*}, \theta^{*}$, then:

(1) If $\theta^{*}=1$, the DMU0 is weak DEA effective (C2R);

(2)If $\theta^{*}=1$, and each optimal solution $S^{-*}=0$, $S^{+*}=0$, then the DMU0 is DEA effective (C2R).

Suppose the said DEA model (C2R) develops under the situation of unchanged returns to scale of private universities, and then the optimal value $\theta^{*}$ obtained is the overall technical efficiency of private universities which can be divided into pure technical efficiency and scale efficiency. Pure technical efficiency reflects the differences of technical application exist in current production point and the production frontier of changed returns to scale of private universities, while scale efficiency reflects the distance between the production frontier of unchanged returns to scale and the production frontier of changed returns to scale. To calculate the pure technical efficiency, a constraint condition $\sum \lambda_{j}=1$ is added in model (1) (this constraint condition allows the emergence of changes in returns to scale), and DEA (C2GS2) model is obtained as follows:

$$
\left\{\begin{array}{l}
\min \sigma \\
s . t . \\
\sum_{j=1}^{n} \lambda_{j} X_{j}+S^{-}=\sigma X_{0} \\
\sum_{j=1}^{n} \lambda_{j} Y_{j}-S^{+}=Y_{0} \ldots \ldots \ldots \ldots \ldots \ldots(2) \\
\sum_{\lambda_{j}} \lambda_{j}=1
\end{array}\right.
$$

According to DEA theory, suppose the the optimal solutions of programming problem (2) are $\lambda^{*}, S^{-*}, S^{+*}$, 
$\sigma^{*}$, and suppose $P^{*}=\theta^{*} / \sigma^{*}$, where $\sigma^{*}$ represents pure technical efficiency of DMU, $P^{*}$ indicates scale efficiency of DMU, then:

(1)If $\sigma^{*}=1$, then DMU0 is weak DEA effective (C2GS2);

(2) ; If $\sigma^{*}=1$, and each optimal solution is $S^{-*}=0, S^{+*}=0$, then DMU0 is DEA effective (C2GS2);

(3)If $\theta^{*}=\sigma^{*}=1$, then DMU0 is DEA technique effective;

(4)If $P^{*}=1$, then DMU0 has unchanged returns to scale;

(5)If $P^{*}<1$, and $\sum_{j=1}^{n} \lambda_{j}{ }^{*}<1$, then DMU0 has increasing returns to scale;

(6) If $P^{*}<1$, and $\sum_{j=1}^{n} \lambda_{j}^{*}>1$, then DMU0 has decreasing returns to scale;

\section{EMPIRICAL ANALYSIS AS WELL AS CONCLUSIONS AND SUGGESTIONS}

\section{A. Construction of Evaluation Index System for}

Educational Resource Efficiency of Private Universities

Private universities are nonprofit organizations whose operating efficiency can be described with no specific production function, and it is mainly surveyed from the perspective of input and output efficiency of educational resources. Resources invested into private universities are mainly the personnel and capital, generally there are three forms as manpower, finance and material, and each form can be divided into multiple categories as well. (1) Manpower input indicator. Mainly includes teaching and research staff and other personnel. (2) Financial input indicators. Finance is invested in the form of money, and is mainly measured using educational funds expenditure. (3) Material input indicator. Mainly described by using the equipment value, real estate value and other fixed assets value. Educational output of private universities primarily includes such three levels as talent cultivation output, scientific research output and social services output.(1) Talent cultivation output indicators. These indicators can be expressed using such two sub-indexes as number of students at school and quality of education. (2) Scientific research output indicators. Research achievements and research funding are the two main indicators for describing the situation of college scientific research. (3) Social service output indicators. As a guide based indicator, social service output indicators include such three indicators as "revenue obtained from transfer of technology and sale of patents to society," "revenue obtained from open libraries, laboratories, teaching facilities and others to the public" and "revenue obtained from providing services of information and consultation to government, enterprises and individuals" [7].

\section{B. Empirical Estimates of Educational Resource Efficiency Evaluation of Private Universities}

In order to investigate the educational resource allocation efficiency of private universities, 10 private universities are selected as research objects, taking the operating condition of various private universities in 2012 as time section for research, and using the input and output index system of educational resource efficiency evaluation for private university constructed, to measure and evaluate of the overall technical efficiency, pure technical efficiency and scale efficiency of the operating condition of various private universities in 2012 adopting DEA model. Of which, the data of various universities come from China Education Yearbook and their publicly available data. Use LING08.0 software to solve the DEA Model for education efficiency evaluation of private universities, with the DEA evaluation results of educational resource efficiency of various private universities in 2012 as shown in "Table 1".

TABLE I. DEA EVALUATION RESUlts OF EdUCATIONAL RESOURCE EFFICIENCY OF 10 CHINESE PRIVATE UNIVERSITIES IN 2012

\begin{tabular}{|l|l|l|l|l|}
\hline \multicolumn{1}{|c|}{ DMU } & \multicolumn{1}{|c|}{$\begin{array}{c}\text { Overall Technical } \\
\text { Efficiency }\end{array}$} & \multicolumn{1}{c|}{$\begin{array}{c}\text { Pure Technical } \\
\text { Efficiency }\end{array} \boldsymbol{\sigma}^{*}$} & Scale Efficiency & $p^{*}$ \\
\hline Private University A & 0.9075 & 1.0000 & 0.9075 & Decreasing returns to scale \\
\hline Private University B & 0.5973 & 0.7765 & 0.7666 & Increasing returns to scale \\
\hline Private University C & 1.0000 & 1.0000 & 1.0000 & Constant returns to scale \\
\hline Private University D & 0.7667 & 1.0000 & 0.7667 & Increasing returns to scale \\
\hline Private University E & 0.6608 & 0.8202 & 0.8057 & Increasing returns to scale \\
\hline Private University F & 0.5403 & 1.0000 & 0.5403 & Increasing returns to scale \\
\hline Private University G & 1.0000 & 1.0000 & 1.0000 & Constant returns to scale \\
\hline Private University H & 0.8457 & 1.0000 & 0.8457 & Increasing returns to scale \\
\hline Private University I & 0.7376 & 0.7564 & 0.9751 & Decreasing returns to scale \\
\hline Private University J & 0.8903 & 1.0000 & 0.8903 & Increasing returns to scale \\
\hline
\end{tabular}




\section{Analysis of Educational Resource Efficiency of Private Universities}

1)Overall Technical Efficiency Analysis. In the DEA model, the overall technical efficiency $\theta^{*}$ is adopted to measure the closeness degree of actual output of the DMU to evaluated to the maximum output on the section of production frontier constituted by all the DMUs under the condition that the investment factors are unchanged.,$\theta^{*}=1$ indicates that actual production activity of the DMU to be evaluated is on the section of production frontier, namely, overall technical efficiency has reached Pareto Optimality; $\theta^{*}<1$ indicates that the utilization of various input factors of the DMU to be evaluated haven't reached the optimal state, and there exist resource waste with a proportion of $\left(1-\theta^{*}\right)$. From the above Table 1, it can be seen that among the 10 private universities to be evaluated in 2012, there are two universities have reached overall technical efficiency DEA effective, accounting for $20 \%$ of the total, indicating that in the operating process in 2012, these 2 private universities have reasonably taken full advantage of their educational resource input, making the output efficiency of various inputs reach the optimal status; while the remaining 8 universities all have invalid DEA overall technical efficiency in 2012, which indicates deviation from the production frontier exist in the education efficiency of various private universities, as they cannot transfer the invested resources into effective output to the largest extent, and there exist efficiency loss, namely waste of resources exist in the school running process.

2) Pure Technical Efficiency Analysis. According to DEA theory, the overall technical efficiency of each DMU can be divided into pure technical efficiency and scale efficiency, of which pure technical efficiency is used to measure the technical efficiency without considering the influence of DMU scale factors, namely the resource allocation efficiency of DMU after excluding scale effect. If the pure technical efficiency $\sigma^{*}=1$, then it indicates the DMU is pure technology effective, that is to say input factors and output factors of DMU are allocated reasonably, and the pure technical efficiency has achieved the Pareto Optimality; if pure technical efficiency $\sigma^{*}<1$, then it indicates that the DMU is pure technical ineffective, namely the allocation of input and output resources are allocated unreasonably. And in the investment-oriented DEA model, the pure technical efficiency can be used to determine the maximum value can be saved by the input factors under given output condition. It can be seen from Table 1 that among the 10 private universities to be evaluated in 2012, 7 universities have achieved pure technical efficiency DEA effective, accounting for $70 \%$ of the total, suggesting that these private universities can achieve rational allocation of resources under current technical mode of educational input factors combination, and also indicates that various private universities attach great importance to the rational allocation of resources due to limited sources of educational input for private universities.

3) Scale Efficiency Analysis. Scale efficiency is used for measuring the matching degree between the volume of input and output factors of DMU and its development stage and scale, which can reflect whether the DMU is in the stage of increasing returns to scale, decreasing returns to scale or constant returns to scale, thereby to determine the if the DMU shall expand or reduce the investment scale, or maintain the current scale of investment unchanged, to obtain higher operational efficiency and economic benefits. From Table 1 it can be seen that among the 10 private universities in 2012, 2 universities maintain their returns to scale unchanged, that is, its input and output are suitable for current scale of development with maximum efficiency of resource allocation; the remaining 8 universities have relatively low scale efficiency which an improper scale efficiency and the root cause for the low overall technical efficiency of the 10 universities. 2 universities are in the state of decreasing returns to scale, which indicates that these universities have reached the possible maximum scale they can achieve, and these universities just rely on expanding scale for development and the space for them the obtain operating efficiency relying on scale effect is narrowing gradually. The remaining 6 universities are in the stage of increasing returns to scale, suggesting that these universities shall get scale benefits through the expanding scale appropriately, thereby to improve educational resource allocation efficiency and school running efficiency.

\section{CONCLUSION}

Based on DEA evaluation of the educational resource efficiency of 10 private universities in China, the following conclusions are obtained in this paper: from the overall situation of the selected 10 sample private universities, the educational resource allocation efficiency of China 's private universities in general is low, of which, the overall technical efficiency and overall scale efficiency of educational resources of private universities is severely low, which is relevant to the short development history and insufficient school running experience of Chinese private universities. On the other hand, pure technical efficiency of private universities is relatively high, which indicates that Chinese private universities have relatively small educational resources with relatively insufficient educational resource investment. As a result, various universities pay attention to taking full use of limited resources; from the perspective of scale efficiency, most private universities is in the stage of increasing returns to scale, indicating that there is still a large space for private universities to expand their scale.

On accountant of the above conclusions, in the process of school running, Chinese private universities shall strengthen internal management, improve the allocation efficiency of educational resources, change the current situation of low overall technology efficiency of private universities, and expand the school running scale appropriately to give play to scale effect according to the university's own advantages in the development strategic level and under the condition of controlling school running risks. At the same time, they shall change school running ideas and concept to develop a connotative development road simultaneously with the expanding scale in a moderately manner. Improve utilization efficiency of educational resources, realize the organic unity of 
school running scale and operating efficiency, to better serve the development of China's higher education.

\section{REFERENCES}

[1] Burton $\cdot R \cdot$ Clark. Higher Education System-- Multinational Study of Academic Organization [M]. Hangzhou: Hangzhou University Press, $1994: 159$.

[2] Kang Ning. Return of Academic Strength in Resource Allocation of Higher Education $[\mathrm{J}]$. Research On Education Tsinghua University, 2004(1) : 40-44.

[3] Zhouwei. Study on Efficiency Loss of Higher Education Resources-taking the University directly under the Ministry of Education as Examples [J]. Modern Education Science, 2006(4) : 149-152.

[4] Liu Yarong. Evaluation and Analyze on School Running Efficiency of Chinese Colleges and Universities [J]. Education \& Economy, 2011(4) : 31-36.

[5] Chen Tong. Evaluation and Study on Input and Output Relative Efficiency of Higher Education in Western Region [J]. Journal of Northwest A\&F University: Social Science Edition, 2012, 3(2): 102106.

[6] Wei Quanling. Data Envelopment Analysis[M]. Beijing: Science Press, 2004.

[7] Li Fuhua. Evaluation Index System of Utilization Efficiency of Higher Education Resources[J]. Journal of Further Education of Shaanxi Normal University, 2000, 17(3): 33-36. 